\title{
Who cares for the patient with head injury now?
}

\author{
I J Swann, A Walker
}

\begin{abstract}
Objective-A recent report on head injury management from the Royal College of Surgeons of England suggests that surgeons are unsuited to the inpatient care of head injuries (ICHI) and should hand over responsibility entirely to neurosurgeons and accident and emergency (A\&E) specialists. This prompted a survey of $A \& E$ consultants to establish their opinions on the current and future practice of head injury care.

Methods-Questionnaires were sent to consultant members of the British Association for Accident and Emergency medicine. Of a possible $256 \mathrm{~A} \& \mathrm{E}$ departments from Great Britain and Ireland with over 20000 annual new attenders $206(80 \%)$ replied.
\end{abstract}

Results-General surgeons contribute to ICHI for adults in 107 of 206 hospitals (52\%) compared with orthopaedic surgeons in 73 of $206(35 \%)$ and A\&E consultants in 71 of $206(34 \%)$. There was frequent criticism that surgeons are uninterested in head injury care. Fifty nine units $(30 \%)$ commented on the lack of neurosurgery beds and difficulties experienced in getting patients accepted. Few hospitals seem to have well integrated rehabilitation or follow up services targeted at head injury. One in six patients with head injury admitted to a general hospital or observation ward remain after 48 hours and one in 20 stay beyond one week. Of the $132 \mathrm{~A} \& \mathrm{E}$ units without responsibility for ICHI 54 $(41 \%)$ either wish to take on this responsibility or are willing to do so if the necessary resources are first put in place. The perceived net revenue cost required to allow $67 \mathrm{~A} \& \mathrm{E}$ units to take on ICHI is about 12.5 million pounds per year. This does not include the cost of further care after 48 hours, follow up or rehabilitation. Conclusion-Only one third of A\&E units at present have even part of the ICHI role recommended in the RCS report; another third are prepared to accept a new role if training and resources are provided and support is forthcoming from other specialists to take over the care after 48 hours; the remaining third are unwilling to accept responsibility for ICHI.

(Emerg Med f 2001;18:352-357)

Keywords: inpatient care; head injury; observation ward Health Board, Glasgow A Walker

Correspondence to: MrSwann (ian.swann@ northglasgow.nhs.scot.uk)

Accepted for publication 12 January 2001 Who cares for the patient with head injury now? This question was posed by Bryan Jennett in the $B M \mathcal{F}$ a quarter of a century ago and by Graham Teasdale in the British fournal of Hospital Medicine in $1985 .{ }^{12}$ Professor
Jennett was concerned that because so many disciplines were involved in the management of head injured patients continuity of care was difficult to achieve. He called for neurosurgeons to provide support for other surgeons who had inpatient head injury responsibility. This support would include training, supervision and, if necessary, visits to surgical wards. $\mathrm{He}$ identified the need for reorganisation of post-primary care - that is, provision of beds where medical supervision can be continued by those who were responsible for the acute phase of treatment. Professor Teasdale suggested that someone, perhaps a community medicine specialist, should take overall regional responsibility for ensuring that locally agreed policies about management are implemented and audited.

These concepts have hardly been developed and a recent report from the Royal College of Surgeons of England highlights the issue. ${ }^{3}$ Although general and orthopaedic surgeons still look after most admitted head injuries it suggests that surgeons are unsuited to this role and should hand over responsibility entirely to accident and emergency (A\&E) specialists and neurosurgeons. ${ }^{34}$

In Britain, $A \& E$ doctors are routinely involved in the early management of head injured patients. At least a third of major $A \& E$ units in the UK have short stay facilities and, although the case mix is very varied, the most common category of patient routinely admitted is minor head injury. ${ }^{5}$ Current practice ranges from departments where $A \& E$ staff have responsibility for only the first few hours of management to those where considerable responsibility is taken for further care and follow up of more severely injured patients.

There is ongoing debate particularly on the question of which specialty should be responsible for the first 48 hours of adult head injury care. Many surgeons feel inadequately trained for the role and with the new specialty registrar programmes it will be extremely unusual for new consultants in surgery to receive formal training in neurosurgery as part of their higher surgical training. ${ }^{3}$ Rather than encouraging surgeons to remedy their lack of training the RCS report recommends a transfer of their head injury responsibility to A\&E specialists. A survey of A\&E consultants' views on training in January 1999 showed that of 48 already committed to ward management 17 (35\%) expressed a need for further training and 31 $(40 \%)$ of 77 without this responsibility would welcome such training. ${ }^{6}$

To further inform this debate on head injury management the views of $\mathrm{A} \& \mathrm{E}$ consultants were sought with the help of the British Association for Accident and Emergency Medicine (BAEM). 


\section{Methods}

In April and July 1999 questionnaires were sent to consultant members of the BAEM for information on the current management of patients with head injuries in their hospitals and their role in head injury care. Adult and paediatric A\&E departments from Great Britain and Ireland with over 20000 annual new attenders were surveyed (BAEM Directory 1998/99). Minor injuries units and those departments without $\mathrm{A} \& \mathrm{E}$ consultant supervision were excluded. There were 256 eligible departments.

Although only one reply was requested from each department, multiple replies were received from a few departments some of which expressed conflicting views on some questions. Where possible the details were discussed with the consultants involved and a consensus view obtained. A consensus was not possible in only six responding departments whose divided views on one or two questions were included within the "unsure" category of replies.

The data from each questionnaire were entered into a Microsoft Access 97 database.

\section{Results}

Data were obtained from 206 (80\%) of the 256 eligible departments represented in the survey.

They ranged in size from 21000 to 124000 new patient attendances per year (mean

Table 1 Annual incidence of head injury (HI) attendance at $A \mathcal{E} E$ and admission to general or observation wards

\begin{tabular}{|c|c|c|c|c|}
\hline & $\begin{array}{l}\text { Actual HI } \\
\text { attenders at } 34 \\
\text { AE E units }\end{array}$ & $\begin{array}{l}\text { Estimated } H I \\
\text { attenders at } 113 \\
A \Theta^{\circ} E \text { units }\end{array}$ & $\begin{array}{l}\text { Actual HI } \\
\text { admissions in } \\
53 \text { hospitals }\end{array}$ & $\begin{array}{l}\text { Estimated HI } \\
\text { admissions in } \\
101 \text { hospitals }\end{array}$ \\
\hline Mean number of HI patients & 3452 & 3547 & 477 & 412 \\
\hline $\begin{array}{l}\text { Mean number of A\&E new } \\
\text { attenders per unit }\end{array}$ & 52260 & 52271 & 52255 & 52663 \\
\hline Mean $\%$ of $\mathrm{A} \& \mathrm{E}$ attenders & 6.6 & 6.8 & 0.91 & 0.79 \\
\hline
\end{tabular}

Table 2 Specialties with some responsibility for inpatient care of head injuries (ICHI)

\begin{tabular}{lcc}
\hline Specialty & $\begin{array}{l}\text { Number (\%) of hospitals where a } \\
\text { specialty may have responsibility for } \\
\text { ICHI (n=206) }\end{array}$ & $\begin{array}{l}\text { Number (\%) of hospitals where a } \\
\text { specialty is the main provider of } \\
\text { beds for ICHI }(n=206)\end{array}$ \\
\hline General surgery & $107(52)$ & $83(40.3)$ \\
Paediatrics & $97(47)$ & $4(1.9)$ \\
Orthopaedic surgery & $73(35)$ & $60(29.1)$ \\
A\&E & $71(34)$ & $47(22.8)$ \\
Neurosurgery & $14(7)$ & \\
Medicine & $4(2)$ & $8(3.8)$ \\
Other & $4(2)$ & \\
Neurology & $3(1.5)$ & $4(1.9)$ \\
Not stated & & \\
\hline
\end{tabular}

Table 3 Inpatient service for head injuries - views of AEE consultants with ICHI. (46 comments from 40 departments, a maximum of two comments per unit were included)

\begin{tabular}{lll}
\hline Issue & Opinion of respondent & $\begin{array}{l}\text { Number of units } \\
\text { commenting }\end{array}$ \\
\hline Surgeons & Poor & 9 \\
$\quad$ quality of inpatient service & Helpful & 3 \\
$\quad$ share responsibility with A\&E & Need easier access to & 7 \\
$\begin{array}{l}\text { Sehabilitation services } \\
\text { Bedfing-experienced nurses and doctors }\end{array}$ & Need more & 6 \\
$\quad$ A\&E beds & Too few or far from A\&E & 5 \\
$\quad$ Orthopaedic and admission beds & Easy access & 2 \\
Length of stay & Current practice & 5 \\
$\quad<24$ hours under A\&E & Inappropriate for A\&E & 2 \\
$\quad$ medium or long term & Reduced by A\&E ward & 2 \\
Clinical risk & & 5 \\
Miscellaneous & & 46 \\
All issues & & \\
\hline
\end{tabular}

52 301). Only 41 (20\%) had 24 hour middle grade cover and only $60(29 \%)$ had three or more A\&E consultants and $54(26 \%)$ had less than two consultants.

The proportion of the responding departments with any beds under A\&E clinical care $(42 \%)$ was the same as that for non-responding departments as recorded in the BAEM directory.

INCIDENCE OF HEAD INJURY ATTENDERS AND ADMISSION RATES

"Actual" figures for head injury attendances in 1998 were provided by 34 A\&E departments and for admissions by 53 departments. The accuracy of such figures can be subject to wide variation because of the different methods of collection of data and different definitions of head injury used within departments. ${ }^{7}$ With this reservation, on average $6.6 \%$ of $A \& E$ new attenders had a head injury and $0.91 \%$ of all new attenders were admitted. These figures are similar to the "estimates" of $6.8 \%$ and $0.79 \%$ made by departments without access to such data (table 1).

The "actual" data show that about one in every seven head injury attenders are admitted from $A \& E$ units. The admission rate is greater $(16 \%)$ for seven units where some patients are admitted under $\mathrm{A} \& \mathrm{E}$ care compared with $11 \%$ for 16 units where patients are admitted only under orthopaedic or general surgeons. Further study would be required to establish the significance of this finding.

INPATIENT CARE OF HEAD INJURIES (ICHI)

In most hospitals several specialties share the responsibility for admitted head injury patients.

General surgeons contribute to ICHI for adults in 107 of 206 hospitals (52\%) compared with orthopaedic surgeons 73 of 206 (35\%) and A\&E consultants 71 of 206 (34\%) (table 2).

It is not surprising that only three (18\%) of the $17 \mathrm{~A} \& \mathrm{E}$ units with less than 30000 new attenders have responsibility for such beds whereas almost half $(44 \%)$ of the larger departments (over 55000 new attenders) have A\&E consultants providing ICHI.

The number of consultants and the presence of 24 hour on site middle grade cover correlate with the existing $A \& E$ responsibility for head injury beds. In general, the larger departments with higher levels of senior staff seem to be more likely to have this responsibility.

\section{VIEWS OF A\&E CONSULTANTS ON ICHI}

Of the 71 hospitals where A\&E consultants already have inpatient responsibility for head injured patients $40(56 \%)$ made comments (table 3) as did 55 (41\%) of the 135 departments without this responsibility.

There were frequent comments that surgeons are uninterested in head injury care, lack the necessary expertise and sometimes fail to admit or send patients for computed tomography according to agreed guidelines. Some recognised that surgical wards had insufficient 
nursing staff for frequent neurological observation. Problems were found with bed availability and the difficulty in accessing rehabilitation services. The benefit of the A\&E specialty taking responsibility for ICHI included reduction of clinical risk but there was concern about having inappropriate responsibility for severely head injured patients particularly those needing long term care.

Radiology

Views were expressed on the service provided by other specialists - many of the favourable comments related to the radiology service. Almost all departments (197 (96\%)) had access to emergency computed tomography 24 hours a day and $175(87 \%)$ were happy with the radiology service for head injured patients, 22 regarding it as an excellent or supportive service. Most adverse comments related to delay or difficulty in access to computed tomography and out of hours reporting.

In 13 hospitals image links to neurosurgery or homes of radiologists were mentioned as being helpful but in five other hospitals this facility was regarded as slow. Eleven respondents expressed concern about the lack of an image link system.

\section{Neurosurgery}

Although most respondents were happy with the neurosurgical service, $59(30 \%)$ were not and 52 of these indicated why. By far the commonest complaint was a lack of neurosurgery beds and difficulties experienced in getting patients accepted.

Only 28 hospitals (14\%) had neurosurgery on site. In five hospitals averaging 53 miles away from a neurosurgical unit transfers were considered to be too long and dangerous.

\section{Paediatrics}

In general it is accepted that all children requiring admission should be under the care of a paediatrician or paediatric surgeon and there were no contrary views expressed in this survey. All of the nine paediatric A\&E departments replied but one was excluded as it had less than 20000 new attenders. One paediatric $\mathrm{A} \& \mathrm{E}$ consultant was exploring the possibility of a six hour observation area in his department, which is the optimal observation time for head injured children suggested by Sainsbury $1984 .^{8}$

LENGTH OF STAY

Data on length of stay were provided by 62 hospitals where A\&E consultants care for head injuries either on $A \& E$ observation, surgical or other wards. In most of these hospitals other specialties also took responsibility for head injured patients. These patients were either transferred from $\mathrm{A} \& \mathrm{E}$ wards or admitted directly from $A \& E$ often with extracranial injuries or more severe head injury.

Only five hospitals seemed to be able to restrict the stay of all their admissions to 48 hours. Of the remaining 57 where A\&E take some ICHI responsibility, on average $13 \%$ of patients stay beyond 48 hours and in 42 units $4 \%$ remained after one week.

Where ICHI was entirely the responsibility of other specialties data on length of stay were obtained from 55 hospitals. In all these units some patients stayed beyond 48 hours (averaging $20 \%$ ) and in 46 hospitals the proportion of patients staying beyond one week was $7 \%$.

These findings concur with those of other UK studies of head injury admissions where patients admitted under surgeons stay longer than those admitted under A\&E. Typically they include more patients with extracranial injuries or medical conditions and they care for a more severe spectrum of head injury than $A \& E$ run beds. ${ }^{39}$ Overall the combined estimated and actual data from $117 \mathrm{~A} \& \mathrm{E}$ units show that at least one in six of head injured patients admitted to a general hospital ward remain after 48 hours and one in 20 stay beyond one week.

FOLLOW UP

Dissatisfaction with follow up arrangements was expressed by half of $A \& E$ consultants with inpatient responsibility but only one third of those without ICHI. This may be because those experienced in ICHI are more likely to perceive the value of follow up particularly for the mild and moderately injured patient. ${ }^{10}$ Several consultants commented on the lack of proper rehabilitation facilities that may lead to delayed discharge of more severely injured patients. Few hospitals seem to have well integrated rehabilitation services targeted at head injury. Some recognise the value of head injury coordinators to integrate the path between hospital care and the community services and organisations such as "Headway", which has an important role in the post rehabilitation care of the head injured and their families.

FUTURE ROLE AND RESPONSIBILITIES

In the section of the questionnaire headed "Your future responsibilities for the management of head injuries" consultants were asked "Do you wish to change your role in any way?" with "Yes/No" options and a section for comments. Most units had no wish to change their role particularly those with ICHI (table 4).

The reasons for change and comments by $\mathrm{A} \& \mathrm{E}$ consultants on their future role are summarised in table 5. Of the 70 units with ICHI where consultants expressed a view on the issue of change 45 made comments. The dominant theme was the need for better staffing and other resources to enable $\mathrm{A} \& \mathrm{E}$ to provide a better ICHI service or at least maintain the present service. Only one unit wished to abandon the responsibility for in patient care.

Table 4 Future responsibilities: opinion of $A \mathcal{E} \cdot E$ consultants with or without ICHI responsibility on the question "Do you wish to change your role in any way?"

\begin{tabular}{llll}
\hline & $\begin{array}{l}\text { ICHI } \\
(n=71)\end{array}$ & $\begin{array}{l}\text { No ICHI } \\
(n=135)\end{array}$ & $\begin{array}{l}\text { All units } \\
(n=206)\end{array}$ \\
\hline Wish change & $21(30 \%)$ & $54(40 \%)$ & $75(36 \%)$ \\
No wish for change & $47(66 \%)$ & $61(45 \%)$ & $107(52 \%)$ \\
Unsure & $2(3 \%)$ & $17(13 \%)$ & $19(9 \%)$ \\
Unrecorded & 1 & 3 & 4 \\
\hline
\end{tabular}


Table 5. AEE E consultant opinion on change of their future role in the inpatient care of head injuries ( ICHI)

\begin{tabular}{|c|c|c|}
\hline Main issue & $\begin{array}{l}\text { Comments from } 45 \\
\text { units with ICHI }\end{array}$ & $\begin{array}{l}\text { Comments from } 51 \text { units without } \\
\text { ICHI who wish to change }\end{array}$ \\
\hline $\begin{array}{l}\text { Resources for ICHI (staff, beds, etc) must } \\
\text { be in place first }\end{array}$ & 16 & 31 \\
\hline Length of stay for A\&E ICHI & & \\
\hline Should be up to 48 hours & 10 & 15 \\
\hline Should be up to 24 hours & 5 & 6 \\
\hline Rehabilitation and follow up & & \\
\hline Facilities need improving & 3 & 3 \\
\hline $\begin{array}{l}\text { Other issues (training, A\&E consultant } \\
\text { responsibility, etc) }\end{array}$ & 17 & 11 \\
\hline All issues & 51 & 66 \\
\hline
\end{tabular}

Of the 132 units without responsibility for ICHI where a view on the issue of change was recorded $54(41 \%)$ either wish to take on this responsibility or are willing to do so if the necessary resources are first put in place. Even those who are enthusiastic about taking on a ward responsibility recognise the need for adequate levels of well trained staff, investment in $\mathrm{A} \& \mathrm{E}$ beds and for other specialties including neurosurgery to provide support and take over the management of patients after 48 hours.

Comments from 25 units where consultants do not wish to take on ICHI and 16 units where they are unsure, mainly related to the resources that are required to provide a proper service for both $A \& E$ patients and short stay head injury patients.

Concerns were expressed about the problem of providing long term care for severely injured patients, the lack of senior A\&E staff and the burden of weekend ward rounds. Others simply felt that $A \& E$ is inappropriate for the ongoing care of these patients and surgeons should be trained to deal with them.

\section{RESOURCE ISSUES}

A major concern expressed by A\&E consultants was the need to ensure proper funding of the head injury service. The question was posed "If your A\&E unit was asked to take responsibility for the in-patient care of HI patients up to 48 hours, what additional resources, if any, would you require?"

Financial information was provided by 160 $(78 \%)$ departments, most requesting additional revenue for extra staff but 31 of these departments indicated a net revenue cost of zero. When costs were not stated but staffing requirements were, the revenue was calculated using the assumed salaries of: consultant $£ 50000$, middle grade doctor $£ 30000$, senior house officer $£ 28000$, one whole time equivalent nurse $£ 15000$ and one clerk $£ 10000$. The main direct revenue cost was that for nursing staff who must be available to carry out

Table 6 Net revenue cost of change identified by AE E units with an opinion on their future role

\begin{tabular}{llllll}
\hline & $\begin{array}{l}\text { A\&E units } \\
\text { with opinion }\end{array}$ & $\begin{array}{l}\text { A\&E units } \\
\text { identifying cost }\end{array}$ & $\begin{array}{l}\text { Mean } \\
\text { cost }(£)\end{array}$ & $\begin{array}{l}\text { Minimum } \\
\text { cost }(£)\end{array}$ & $\begin{array}{l}\text { Maximum } \\
\text { cost }(£)\end{array}$ \\
\hline ICHI and no wish to change role & 47 & 34 & 90824 & 0 & 350000 \\
ICHI and wish to change role & 21 & 17 & 146118 & 0 & 500000 \\
No ICHI and no wish to change role & 61 & 56 & 176243 & 0 & 429000 \\
No ICHI and wish to change role & $54^{\star}$ & 53 & 186632 & 0 & 600000 \\
All A\&E units & 183 & 160 & 158332 & 0 & 600000 \\
\hline
\end{tabular}

^Four of these units identified zero net cost for change (one unit could not estimate a cost). frequent careful observations particularly in the first 24 hours of care.

Ten units provided data on capital costs such as the need to build new wards close to the A\&E department. The average capital requirement by these 10 units was $£ 494000$.

There was little confidence in the concept of money being transferred from surgical specialties in return for taking over some or all of their responsibility for inpatient care although 28 departments indicated that an average of $48 \%$ of their additional revenue costs could be transferred. Eight of these units considered $100 \%$ of the revenue costs could be transferred but no evidence for the likelihood of achieving that aim was presented. Only one department indicated that they could simply take over responsibility for existing beds from surgeons hence there would be no net increase in the running costs of the beds.

If the transferrable revenue costs suggested by $A \& E$ consultants are valid, the perceived net revenue costs for those 54 units willing to take on ICHI amount to an average of $£ 186632$ per trust (table 6 ). The considerable variation in the perceived costs $(£ 0-£ 600000)$ is partly because of the variability of existing $A \& E$ resources and local practice but may also reflect the different methods of calculating the cost, for example, most respondents did not clearly separate the cost of staffing beds for head injuries from that of other patients in the A\&E ward. Departments that are currently hard pressed may understandably demand more resources in return for taking on extra work.

If the 50 non-responding hospitals are similarly disposed to the 206 responders this would add another 13 hospitals to the 54 who wish to take on the new role. The perceived net revenue cost required to allow $67 \mathrm{~A} \& \mathrm{E}$ units to take on ICHI is about $£ 12.5$ million per year.

\section{Discussion}

The survey results represent views and data from over $80 \%$ of the major A\&E units in the UK. The incidence of head injury attendance (averaging $7 \%$ of all $\mathrm{A} \& \mathrm{E}$ new attenders) is lower than the often quoted figure of $11 \%$, which was based on a thorough review of records of $3558 \mathrm{~A} \& \mathrm{E}$ patients from 40 Scottish hospitals. ${ }^{11}$ This is partly because the routine head injury data available to $A \& E$ consultants under records mild head injury particularly when associated with other injuries. This failure to record the diagnosis of head injury was noted by Moss in 1996 for patients admitted to trauma service beds in Oxford. ${ }^{12}$

The RCS report found that patients could be transferred or discharged from $A \& E$ short stay facilities within 48 hours in 64 of 93 units (69\%) but in this survey complete compliance with this aim was achieved in only $11 \%$ (4 of 36) of units with short stay beds, 5 of $62(8 \%)$ of those with $\mathrm{A} \& \mathrm{E}$ controlled beds and in none of the 55 wards under surgical or non-A\&E care. "Actual" data from 22 hospitals in this study show that $21 \%$ stay beyond 48 hours and $8 \%$ beyond one week. This is supported by a study in five Glasgow hospitals entailing 
thorough review of the case records of 3000 hospitalised adult head injuries that showed $29 \%$ remaining beyond 48 hours and 9\% beyond one week. ${ }^{9}$

Although only 28 (22\%) of the 129 departments who estimated the additional revenue required indicated the possibility of money being transferred from other specialties in return for taking over the responsibility for in patient care, some transfer of resources would seem logical and could be explored by trust chief executives or on a national basis.

Some A\&E consultants, particularly in small units, cannot be expected to take on ICHI and will continue to rely on other specialties for the service. The disadvantages of economy of scale in trying to provide a comprehensive service for a small workload of head injured patients has to be recognised and where appropriate amalgamation of smaller departments may provide a solution. Larger units should admit sufficient patients to allow medical and nursing staff to maintain the necessary level of expertise in head injury care. The proximity of head injury beds to the $\mathrm{A} \& \mathrm{E}$ department is also a factor that particularly concerns those considering taking on ICHI. At present 45 $(64 \%)$ of the 70 departments with ICHI have beds within a one minute walk of $A \& E$ and only $33(47 \%)$ are in or adjacent.

Any unit prepared to take on the additional responsibility must be sure that they have both the training and experience to do so as well as the resources. Clinical governance demands that we pay more attention to the development and maintainance of clinical standards. Both $\mathrm{A} \& \mathrm{E}$ consultants and surgeons recognise a lack of training in head injury care. ${ }^{36}$ The nature of training and support requested by $\mathrm{A} \& \mathrm{E}$ consultants includes "closer liaison/working relationship with neurosurgeons", "refresher courses/CME in HI management", "intermediate HI management", and "rehabilitation". ${ }^{6}$

General and orthopaedic surgeons are still the main providers of ICHI for adults admitted to non-neurosurgical wards. Some are perceived as uninterested or providing suboptimal care and this should not be resolved by surgeons withdrawing completely from the care of this important group of trauma patients.

$\mathrm{A} \& \mathrm{E}$ doctors have a key role in head injury management and are well placed to work with surgeons and other specialists in developing the head injury service.

In 1984 Teasdale recognised that neurosurgeons should be more ready to accept more patients sooner but there was a need to ensure that A\&E staff did not abuse this trend. ${ }^{13}$ Since then the more widespread use of computed tomography in general hospitals before referral should have helped decision making but $\mathrm{A} \& \mathrm{E}$ consultants in this survey were frequently concerned about delay in decision making before accepting patients. Neurosurgeons are expected to provide more support for general hospitals and develop rehabilitation services.

The workload of head injury care in a general hospital can be considerable and certainly not restricted to the first 48 hours. Those A\&E departments wishing to take on ICHI need reassurance that the training and resources will be provided and that support will be forthcoming from other specialists to take over the care after 48 hours.

\section{Conclusion}

The ICHI issue is important for doctors, managers, politicians and especially for patients. $\mathrm{A} \& \mathrm{E}$ consultants regularly participate in the care of head injury patients and appreciate the potential morbidity that may easily result from suboptimal management of this often difficult type of patient. Some would be willing to take over the responsibility of the first 48 hours of care from surgeons but not without the necessary funding to staff observation beds and the support of other specialties. If resources were first put in place there would probably be support from two thirds of $A \& E$ units for the $A \& E$ specialist to manage the first $24-48$ hours of in patient care. The other third would support alternative arrangements that would entail surgeons continuing to take responsibility. It is probable that surgeons will continue to be involved in trauma care and with patients who have head injuries at least as a secondary diagnosis. They will continue to need training to equip them to treat such patients.

Given governmental support the $\mathrm{A} \& \mathrm{E}$ specialty would be enthusiastic in continuing to develop the head injury service in close collaboration with their radiology, surgical and neurosurgical colleagues. In any case, it is necessary for all clinicians responsible for patients with head injury to ensure they maintain their knowledge of and commitment to head injury care.

We would like to thank Jennifer Mills, clinical audit officer Glasgow Royal Infirmary University NHS Trust for help with the creation and analysis of the database; Susan Groom, business manager GRI University NHS Trust for her advice on resource issues; Julie Bloomfield, BAEM secretariat for distributing the questionnaires and Rachael Swann for helping to uting the questionnaires and Rachael Swann for helping to retrieve replies by telephone reminders. We are particularly grateful to all the A\&E consultants who responded to the ques-

Contributors

Ian Swann was responsible for initiating the survey and took overall responsibility for the correlation of the results and interpretation of the data. He will act as guarantor. Andrew Walker advised on the health economics aspects of the paper.

Funding: none.

Conflicts of interest: none.

1 Jennett B. Who cares for head injuries? BMF 1975;iii:26770

2 Teasdale G. Who cares about head injuries? Br f Hosp Med 1985;33:67.

3 Royal College of Surgeons of England. Report of the Working Party on the Management of Head Injuries. London: Royal College of Surgeons of England, June 1999.

4 Collins REC, Cashin PA. General surgeons and the management of head injuries. Ann $R$ Coll Surg Engl 1999;81:151-3

5 Goodacre SW. Role of the short stay observation ward in accident and emergency departments in the United Kingdom. F Accid Emerg Med 1998;15:26-30.

6 Wan A. Suitability of accident and emergency consultants to manage admitted head injury patients. [Abstract]. 7 Accid Emerg Med 1999;16:386-7.

7 Deb S. ICD-10 codes detect only a proportion of all head injury admissions. Brain Injury 1999;13:369-73.

8 Sainsbury C, Sibert J. How long do we need to observe head Sainsbury C, Sibert J. How long do we need to obser
injuries in hospital? Arch Dis Child 1984;59:856-9.

9 Thornhill S, Teasdale GM, Murray G, et al. High incidence of disability after admission with a head injury: the of disability after admission with a head injury: the
importance of "mild" injuries. BMF 2000;320:1631-5. 
10 Wade DT, King NS, Wenden FJ, et al. Routine follow up after head injury: a second randomised controlled trial. $\mathcal{F}$ after head injury: a second randomised cont
Neurol Neurosurg Psychiatry 1998;65:177-83.

11 Strang I, MacMillan R, Jennett B. Head injuries in accident and emergency departments at Scottish hospitals. Injury 1978;10:154-59.
12 Moss NEG, Wade DT. Admission after head injury: how many occur and how many are recorded? Injury 1996;27: many occur.

13 Teasdale G. Head injuries are badly managed in A\&E departments and neurosurgeons are partly to blame. Arch Emerg Med 1984;3:123-34.

\section{7th European Forum on Quality Improvement in Health Care}

\section{1-23 March 2002 \\ Edinburgh, Scotland}

We are delighted to announce this forthcoming conference in Edinburgh. Authors are invited to submit papers (call for papers closes on Friday 5 October 2001) and delegate enquiries are welcome.

The themes of the Forum are:

- Leadership, culture change, and change management

- Achieving radical improvement by redesigning care

- Health policy for lasting improvement in health care systems

- Patient safety

- Measurement for improvement, learning, and accountability

- Partnership with patients

- Professional quality: the foundation for improvement

- Continuous improvement in education and training

- People and improvement.

Presented to you by the BMJ Publishing Group (London, UK) and Institute for Healthcare Improvement (Boston, USA). For more information contact: quality@bma.org.uk or look at the website www.quality.bmjpg.com. Tel: +44 (0)20 7383 6409; fax: +44 (0)20 73736869 . 